\title{
Morfo-anatomia de frutos secos em espécies de Apocynaceae: significado ecológico e evolutivo
}

\author{
Sueli Maria Gomes ${ }^{1}$
}

Recebido em 28/03/2007. Aceito em 8/08/2007

\begin{abstract}
RESUMO - (Morfo-anatomia de frutos secos em espécies de Apocynaceae: significado ecológico e evolutivo). Frutos secos predominam entre as espécies de Apocynaceae, especialmente aqueles do tipo folículo, apontado na literatura para Aspidosperma parvifolium A.DC., Mesechites mansoana (A.DC.) Woodson e Prestonia coalita (Vell.) Woodson. Frutos fechados e abertos destas espécies foram examinados anatomicamente com o objetivo de confrontar suas características com aquelas de outras espécies da família. Constatou-se que os frutos de $P$. coalita são cápsulas bicarpelares septicidas, significando a presença de dois tipos de frutos neste gênero, em lugar de apenas um, como se pensava anteriormente. Cápsulas podem estar presentes em outras espécies de Prestonia e em outros gêneros da família relatados como tendo folículos. Para Apocynaceae, alguns caracteres taxonômicos devem ser considerados, como espessura e número de camadas das regiões e sub-regiões do pericarpo; presença de aerênquima, esclereídes, fibras longitudinais não-lignificadas ou idioblastos secretores no mesocarpo; posicionamento dos feixes vasculares no mesocarpo; espessura do endocarpo e orientação de suas fibras; presença de costas internas no pericarpo. Adicionalmente, discutiu-se sobre o papel das costas internas do pericarpo e das fibras nãolignificadas do mesocarpo para o mecanismo xerocástico. Desenvolveu-se um teste de desidratação total para determinar a curvatura máxima do pericarpo, relacionando as implicações com a deiscência.
\end{abstract}

Palavras-chave: deiscência, folículo, cápsula, evolução, Cerrado

\begin{abstract}
Morphoanatomy of dry fruits in Apocynaceae species: ecological and evolutionary significance). Dry fruits predominate in Apocynaceae species, especially the follicle type reported for Aspidosperma parvifolium A.DC., Mesechites mansoana (A.DC.) Woodson and Prestonia coalita (Vell.) Woodson. Anatomical analysis of intact and open fruits was carried out to compare characteristics with those of other species of this family. We found that the fruit of $P$. coalita is a bicarpellary septicidal capsule, showing that this genus has two types of fruits instead of one as previously thought. Capsules may be found in other Prestonia species and in other Apocynaceae genera reported as having follicles. For Apocynaceae, some taxonomic characters should be considered such as thickness and number of pericarp layers and sublayers; presence of aerenchyma, sclereids, non-lignified fibres, secretory idioblasts in the mesocarp; vascularbundle position in the mesocarp; endocarp thickness and fibre orientation; presence of internal ribs in the pericarp. Furthermore, the role of the internal ribs of the pericarp, as well as the non-lignified mesocarp fibres for the xerocastic mechanism are discussed. A total dehydration test was developed to determine maximum pericarp curvature and its implications for the dehiscence process.
\end{abstract}

Key words: dehiscence, follicle, capsule, evolution, Cerrado

\section{Introdução}

Apocynaceae Adans. circunscreve ca. 400-480 gêneros e 4.300-4.800 espécies com distribuição pantropical e em climas temperados (Albers \& Meve 2001; Potgieter \& Albert 2001). São árvores, arbustos, ervas ou lianas latescentes, com flores 5-meras, tubulosas e com gineceu bicarpelar (Judd et al. 1999; Endress \& Bruyns 2000; Souza \& Lorenzi 2005). Os tipos de frutos apontados para esta família são folículo, cápsula, drupa, raramente baga, sendo folículo o mais freqüente; as sementes são comosas ou não, às vezes aladas ou ariladas (Barroso et al. 1999; Endress \& Bruyns 2000; Simões \& Kinoshita 2002).

Os frutículos em Apocynaceae geralmente são gêmeos, ou eventualmente solitários por aborto de um dos ovários (Torres \& Galetto 1999; Simões \& Kinoshita 2002), apresentando morfologia variável entre as espécies. Nas árvores de Aspidosperma parvifolium A.DC., o folículo é dolabriforme e achatado, contendo em seu interior sementes aladas (Woodson Jr. 1951; Duarte 1970; Marcondes-Ferreira \& Kinoshita 1996). Em contraposição, Mesechites mansoana (A.DC.) Woodson e Prestonia coalita

\footnotetext{
1 Universidade de Brasília, Departamento de Botânica, Campus Universitário Darcy Ribeiro, Asa Norte, C. Postal 04457, 70910-970 Brasília, DF, Brasil (smgomes@unb.br)
} 
(Vell.) Woodson são lianas que possuem frutos subcilíndricos, bastante alongados e estreitos, abrigando sementes comosas em seu interior (Woodson Jr. 1936; Kinoshita 2005).

Frutos de espécies de Apocynaceae sensu stricto - s.s. - foram enfocados em trabalhos anatômicos, como Catharanthus roseus (L.) G. Don (Zala et al. 1976) e Aspidosperma polyneuron Müll. Arg. (Souza \& Moscheta 1992). Thomas \& Dave (1991) examinaram a anatomia de frutos de Nerium indicum Mill. (= N. oleander L.), tendo posteriormente ampliado seus estudos para doze espécies de Apocynaceae s.s. (Thomas \& Dave 1994). O mecanismo xerocástico de deiscência do fruto de A. megalocarpon Müll. Arg. foi abordado por Hoffmann (1931 apud Roth 1977). Folículos de diferentes espécies de Asclepiadoideae, a subfamília mais derivada de Apocynaceae sensu lato - s.l., foram examinadas anatomicamente: Tylophora dalzellii Hk.f. (Kuriachen et al. 1990), Calotropis procera (Ait.) Ait.f. (Kuriachen et al. 1991) e C. gigantea (L.) Driand. (Kuriachen et al. 1992).

As espécies aqui propostas para estudo ainda não foram objeto deste tipo de abordagem, especialmente Prestonia coalita, descrita com fruto folicular (Woodson Jr. 1936; Simões \& Kinoshita 2002; Rio \& Kinoshita 2005), mas cujo fruto parece ter os carpelos conatos. Os gêneros a serem analisados posicionamse diferentemente dentro da filogenia de Apocynaceae s.l., sendo que Aspidosperma (Alstonieae, Rauvolfioideae) é mais basal, enquanto que Prestonia (Echiteae, Apocynoideae) insere-se em uma tribo mais derivada (Endress \& Bruyns 2000) e Mesechites (Mesechiteae, Apocynoideae) ocupa posição intermediária (Endress \& Bruyns 2000; Simões et al. 2004). Os três gêneros estão circunscritos dentro do que se pode chamar de Apocynaceae s.s. (Rauvolfioideae e Apocynoideae), que exclui as Asclepiadoideae, Periplocoideae e Secamonoideae.

Os estudos anatômicos sobre frutos em Apocynaceae s.l. têm lacunas quanto às relações entre a estrutura do pericarpo e os mecanismos de deiscência, possíveis caracteres úteis taxonomicamente, ou mesmo aspectos evolutivos. O presente trabalho propõe-se a estudar a anatomia do fruto de três espécies de Apocynaceae s.s., Aspidosperma parvifolium, Mesechites mansoana e Prestonia coalita, com o objetivo de confrontar suas características com as de outras espécies da família e efetuar uma abordagem ecológica e evolutiva construída a partir de dados próprios e da literatura. Estas espécies ocorrem em diversos estados do Brasil (Vasconcellos \& Gouvêa 1993; Costa et al. 2004; Kinoshita 2005), especialmente em fisionomias do Cerrado e representam extremos morfológicos do tipo de fruto seco presente na família.

\section{Material e métodos}

Frutos adultos de três espécies de Apocynaceae s.s. foram fixados em FAA (Johansen 1940) imediatamente após a coleta, com as seguintes exsicatas testemunhas: Aspidosperma parvifolium, Gomes 656 (UEC 142189); Mesechites mansoana, Aguiar 1 (UEC 118812) e Prestonia coalita, Gomes 480 (UEC 142063). As amostras foram submetidas a uma bomba de vácuo por $24 \mathrm{~h}$, desidratadas em etanol $50 \%$ por 24 h e estocadas em etanol $70 \%$.

Obteve-se a porção transverso-mediana de cada fruto fixado, sendo que a porção do folículo de A. parvifolium foi fracionada em três partes, abrangendo as regiões dorsal, da costa (lateral mediana) e ventral. O material foi desidratado em série etanólica e incluído em resina plástica (HistoresinLeica). Secções transversais (ST) e longitudinais (SL) foram obtidas através de micrótomo rotativo manual com navalha tipo "C" e coradas com Azul de Toluidina a $0,05 \%$ em tampão acetato $\mathrm{pH} 4,7$. A montagem das lâminas foi feita em resina sintética. Os resultados foram documentados através de fotomicroscópio Olympus BX50. O filme revelado foi escaneado para o uso das imagens digitais.

Frutos abertos das três espécies foram hidratados e sua porção mediana foi seccionada em micrótomo de mesa; as ST foram coradas com Floroglucina (Johansen 1940) ou usadas no teste de desidratação total do pericarpo. Este último constou de desidratação gradativa das ST até etanol 50\%, seguida de coloração com Safranina a $1 \%$ por 20 s. Prosseguiu-se a desidratação dos cortes até álcool $100 \%$ e as lâminas foram montadas com óleo de imersão. Estes resultados foram documentados através do fotomicroscópio Zeiss Axioskope, acoplado a um computador com sistema de captura de imagens ProImage 2.0. Exsicatas testemunhas: A. parvifolium: Duarte 18040 (UB 10467-1); M. mansoana: Melo et al. 870 (UB 12977); P. coalita: Souza et al. 2906 (UB 27296).

Material adicional examinado para a descrição da morfologia externa: Aspidosperma parvifolium: Heringer 5825 (UB 11738); Belém \& Pinheiro 2569 (UB 14125); Mesechites mansoana: Irwin et al. 27761 (UB 18774), Anderson 9728 (UB 18775); 
Prestonia acutifolia (Benth. ex Müll.Arg.) K.Schum.: Irwin et al. 26884 (UB 18863); P. coalita: Irwin et al. 17596 (UB 65173), Irwin et al. 27356 (UB 18869), Anderson 9130 (UB 18867); Temnadenia violacea (Vell.) Miers: Guedes 502 (UB 18909), Anderson 11172 (UB 18907).

As características dos frutos foram descritas a partir de observações feitas no campo e do exame das exsicatas e das secções anatômicas. Adotou-se o conceito mais abrangente de epicarpo, mesocarpo e endocarpo usado por Thomas \& Dave (1991; 1994). A nomenclatura incluiu o conceito de regiões interna e externa das partes do pericarpo adotado para legumes (Pietrobom \& Oliveira 2004) e região mediana, quando foi identificada uma estratificação adicional. Adotouse a classificação de Endress \& Bruyns (2000), com as modificações apontadas por Simões et al. (2004).

\section{Resultados}

Aspidosperma parvifolium (Fig. 1-9): pares de folículos livres entre si, exceto por uma pequena região na base, ou geralmente solitários por aborto de um dos carpelos; folículo dolabriforme e achatado, zigomorfo, ereto, lenhoso, glabro, ca. 2,4 vezes mais comprido do que largo, ca. $(60 \times 25 \times 2) \mathrm{mm}$, estipe ca. $1 \mathrm{~cm}$ (Fig. 1-2). Região mediana do fruto sem diferenças marcantes entre as porções dorsal, da costa e ventral do pericarpo, exceto na zona de deiscência; pericarpo com ca. $6 \mathrm{~mm}$ de espessura; exocarpo constituído por epiderme unisseriada, com lenticelas redondas, contrastantes (Fig. 4), além de colênquima com 6-8 camadas celulares (Fig. 3-4); mesocarpo com ca. 32-34 camadas de células predominantemente parenquimáticas, pequenos grupos de esclereídes amplamente dispersos em meio ao parênquima (Fig. 3, 7), diversos canais laticíferos largos, eventualmente ramificados (Fig. 6), feixes vasculares concêntricos anficrivais (Fig. 3, 8); endocarpo composto por 13-18 camadas de fibras (Fig. 5, 8) com lignificação tardia (Fig. 9) e orientadas diferenciadamente em camadas de espessura muito variável, sendo o endocarpo externo com ca. 3-8 camadas de fibras longitudinais, o endocarpo mediano com ca. 9-10 camadas de fibras transversais ou oblíquas e o endocarpo interno com ca. 1-2 camadas de fibras transversais; zona de deiscência com epiderme diferenciada (Fig. 7). A deiscência é marginicida, as longas e estreitas placentas com ca. $(17 \times 0,5) \mathrm{mm}$ se rompem liberando as sementes aladas (Fig. 2).

Mesechites mansoana (Fig. 10-15): pares de folículos livres entre si, exceto por uma curta região na base; folículo subcilíndrico e longo, delgado, actinomorfo, pêndulo, sublenhoso, glabro, ca. 50 vezes mais comprido do que largo, ca. $(155 \times 3 \times 0,3) \mathrm{mm}$, não estipitado (Fig. 10). Região mediana do fruto com pericarpo com ca. 230-280 $\mu \mathrm{m}$ de espessura; exocarpo constituído por epiderme unisseriada (Fig. 11), lenticelas esparsas, estômatos esparsos; mesocarpo com ca. 14-18 camadas, sendo uma hipoderme uniestratificada e secretora (idioblastos) e os demais estratos constituídos por células parenquimáticas com idioblastos numerosos (Fig. 11), canais laticíferos estreitos e raros (Fig. 12); feixes vasculares bicolaterais, sendo 9 de calibre maior e 10 menores, com grupos de fibras não-lignificadas e de parede espessa adjacentes aos feixes e externos a estes (Fig. 11, 13, 15); floema interno mais abundante do que o externo (Fig. 11); endocarpo composto por ca. 5 camadas de fibras lignificadas e orientadas diferenciadamente, sendo ca. 3 longitudinais no endocarpo externo e ca. 2 camadas de fibras transversais no endocarpo interno (Fig. 11-13), exceto perto da zona de deiscência, onde ocorrem grupos de fibras exclusivamente longitudinais. O pericarpo totalmente desidratado tem ca. 210-260 $\mu \mathrm{m}$ de espessura e abre-se ficando quase plano (Fig. 14), mas ainda com o endocarpo em posição interna e o exocarpo, externo; as fibras longitudinais nãolignificadas do mesocarpo ficam com as paredes colabadas (Fig. 15). O fruto apresenta deiscência marginicida, quando o eixo placentário é liberado do pericarpo, que se abre e expõe este eixo com suas sementes comosas ao vento, liberando-as.

Prestonia coalita (Fig. 16-26): dois carpelos unidos entre si; cápsula bicarpelar septicida subcilíndrica e longa, delgada, actinomorfa, levemente moniliforme, pêndula, sublenhosa, pubérula a glabrescente, ca. 180 vezes mais comprida do que larga, ca. $(540 \times 3 \times 0,2) \mathrm{cm}$, não estipitada (Fig. 16-18). Região mediana do fruto com pericarpo com ca. 120-250 $\mu \mathrm{m}$ de espessura; exocarpo constituído por epiderme unisseriada, com tricomas simples, curtos e muito esparsos, lenticelas esparsas, estômatos esparsos, além de uma camada de colênquima, predominantemente com paredes celulares anticlinais e periclinais externas mais espessas que as paredes periclinais internas (Fig. 19, 21); mesocarpo com ca. 8-11 camadas, sendo mesocarpo externo com ca. 4-6 camadas de parênquima (Fig. 19), mesocarpo mediano com um anel descontínuo e irregular de 4-5 camadas de fibras não-lignificadas longitudinais e de parede espessa (Fig. 19-20, 24), seguido pelo mesocarpo interno 
com ca. 5-7 camadas de células parenquimáticas e feixes vasculares bicolaterais, sendo 9 de calibre maior e 10 menores; floema interno mais abundante do que o externo (Fig. 20, 23); canais laticíferos muito estreitos e raros em meio ao parênquima; endocarpo formado por ca. 1-2 camadas de fibras transversais a levemente oblíquas, exceto por grupos de fibras longitudinais adjacentes à zona de deiscência (Fig. 23). Zona de conação carpelar com continuidade histológica (Fig. 22-23) e homogênea. O pericarpo totalmente desidratado tem ca. 80-130 $\mu \mathrm{m}$ de espessura, apresentando-se completamente dobrado para trás, com o quê o endocarpo passa a ser externo (Fig. 25-26); as fibras longitudinais não-lignificadas do mesocarpo ficam com as paredes colabadas (Fig. 26). A deiscência é septicida (Fig. 18, 22-23, 25). A diferenciação do tecido de separação ocorre na zona de conação entre os carpelos (Fig. 22-23) e depois na sutura carpelar. Com a ruptura sutural, rompe-se o tênue ponto de ligação do pericarpo com o eixo placentário (Fig. 23). O pericarpo abre-se e expõe este eixo com suas sementes comosas ao vento, liberando-as.

P. acutifolia: cápsula bicarpelar septicida subcilíndrica e longa, levemente moniliforme, sublenhosa, glabra, ca. 65 vezes mais comprida do que larga, ca. $(200 \times 3 \times 0,2) \mathrm{mm}$, não estipitada, com deiscência septicida, liberando o eixo placentário e as sementes.

Temnadenia violacea: cápsula bicarpelar septicida cilíndrica e longa, sublenhosa, glabra, ca. 30 vezes mais comprida do que larga, ca. $(150 \times 5 \times 0,2) \mathrm{mm}$, não estipitada, com deiscência septicida, liberando o eixo placentário e as sementes.
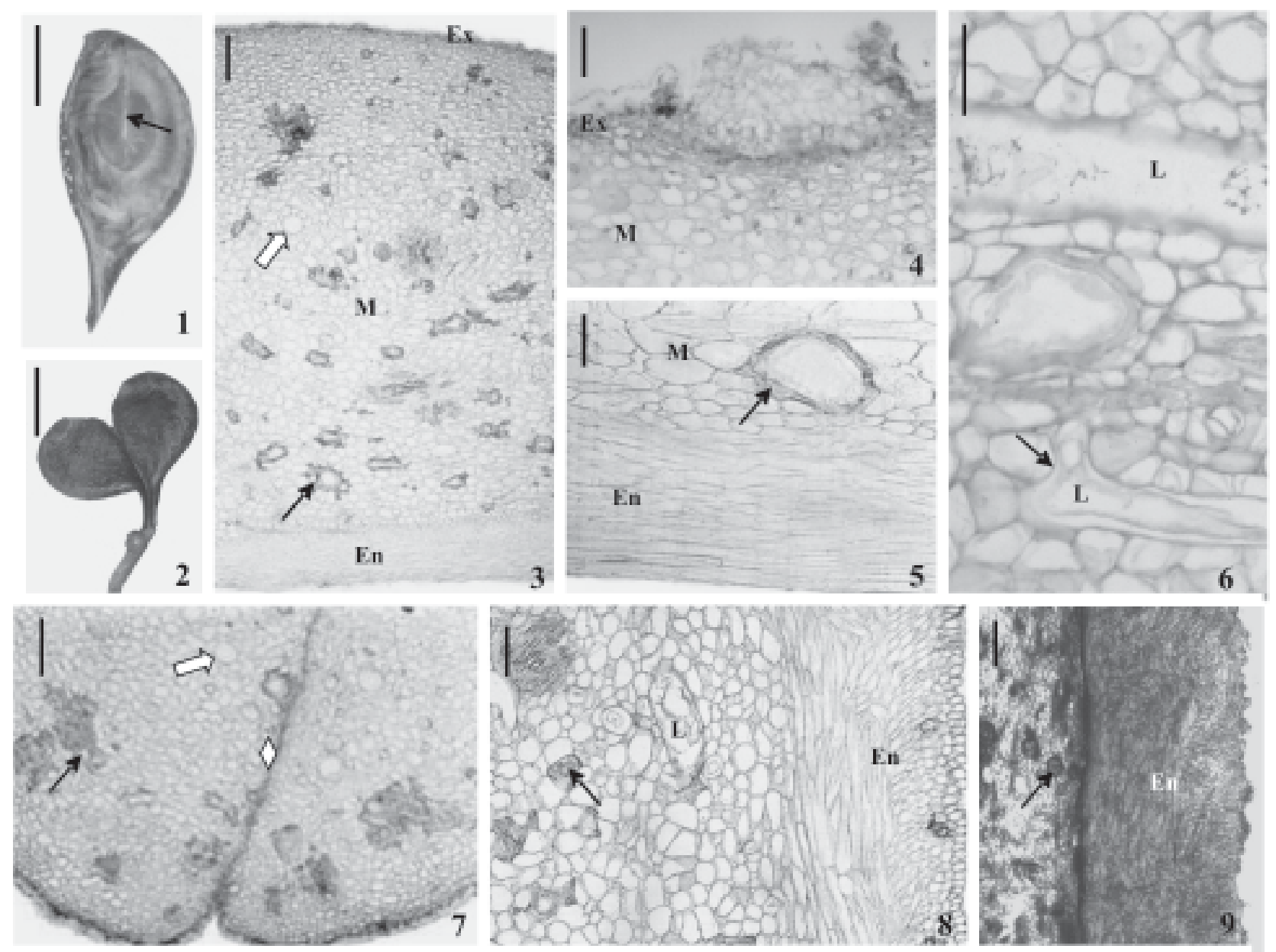

Figuras 1-9. Aspidosperma parvifolium A.DC. 1. Folículo dissecado: placenta (seta). 2. Folículo solitário aberto. 3-9. Pericarpo (3-7: ST; 8-9: SL): esclereídes (3, 5, 7-9, setas pretas) e laticíferos numerosos ( 3,7 , seta branca); lenticela (4); fibras com diferentes orientações no endocarpo (5, 8-9); ramificação no laticífero (6, seta); linha de deiscência (7, losango). 1, 3-8. Frutos adultos fechados. 2, 9. Frutos abertos. 3-8. Azul de Toluidina. 9. Floroglucinol. En: endocarpo, Ex: exocarpo, L: laticífero, M: mesocarpo. Barras = 1-2: 2 cm; 3, 7: $500 \mu \mathrm{m} ; 4: 100 \mu \mathrm{m} ; 5-6,8-9: 200 \mu \mathrm{m}$. 


\section{Discussão}

O estudo anatômico enfocou os frutos secos e deiscentes de três espécies de Apocynaceae, representando variações morfológicas encontradas na família. Em Aspidosperma parvifolium (Fig. 1-9) e Mesechites mansoana (Fig. 10-15), o ovário do gineceu bicarpelar origina dois mericarpos monocarpelares, com deiscência marginicida, às vezes ocorrendo aborto de um dos carpelos na primeira espécie. Segundo Barroso et al. (1999), estas características se encaixam em frutos múltiplos livres ou frutos simples, do tipo folículo. Outra interpretação é que se tratade um esquizocarpo do tipo folicário (Spjut 1994). Estes frutos são aqui descritos como pares de folículos (gêmeos) ou solitários.

O fruto de Prestonia coalita tem sido referido como sendo um par de folículos (Simões \& Kinoshita 2002), algumas vezes ditos "unidos no ápice" até o momento da deiscência (Woodson Jr. 1936; Markgraf 1968; Rio \& Kinoshita 2005). Aqui se demonstrou que nesta espécie o fruto é uma cápsula bicarpelar, pois seus dois carpelos permanecem unidos em toda a sua extensão (Fig. 16-17) e não apenas no ápice, apresentando continuidade histológica na zona de conação carpelar (Fig. 22-23) até o momento da deiscência septicida (Fig. 18). Esta é a primeira caracterização deste tipo de fruto em Prestonia, um gênero neotropical com ca. 60 espécies (Morales 1997; Rio \& Kinoshita 2005).
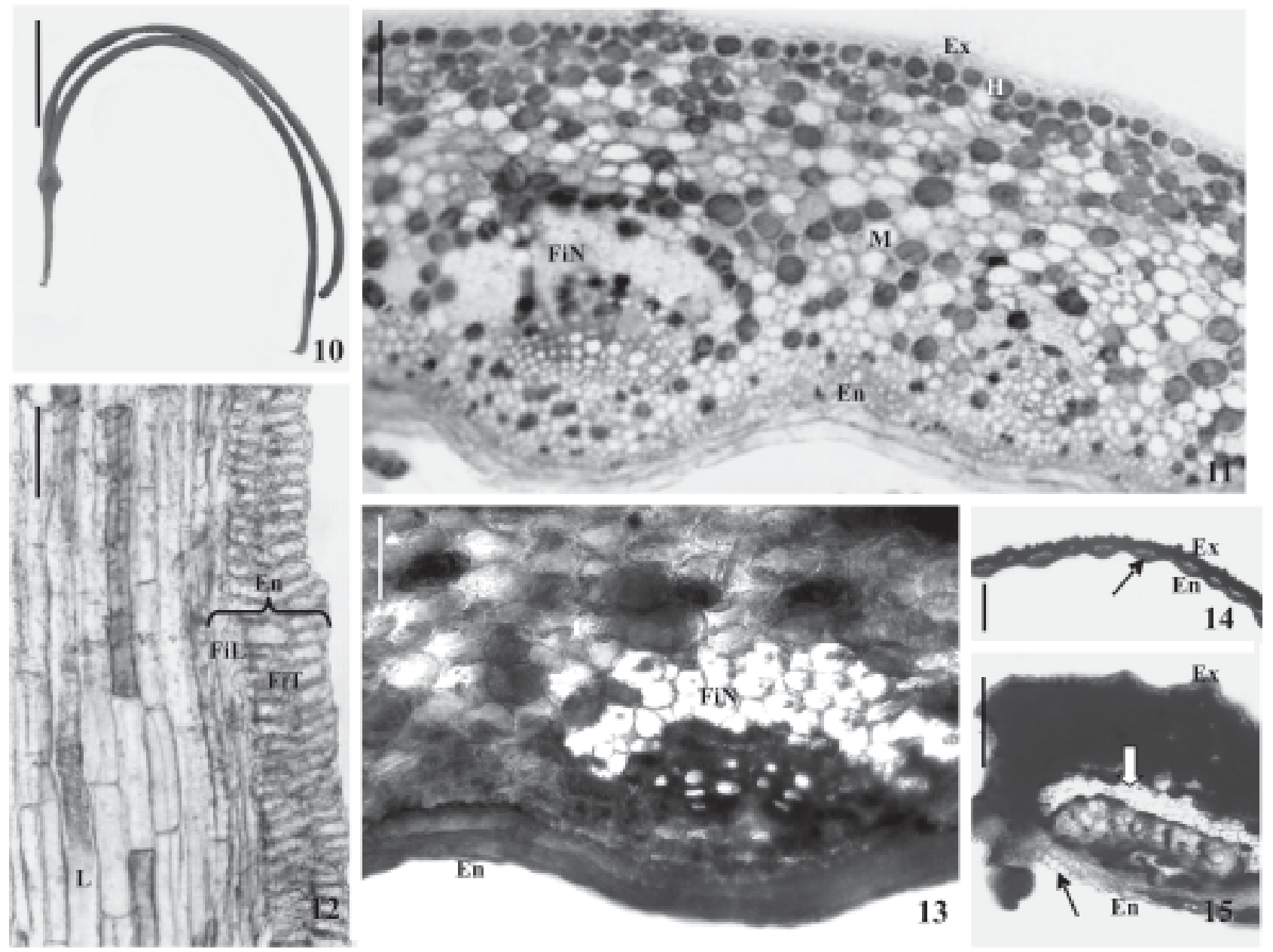

Figuras 10-15. Mesechites mansoana (A.DC.) Woodson. 10. Folículos gêmeos. 11-15. Pericarpo (11, 13-15: ST; 12: SL): fibras longitudinais não-lignificadas no mesocarpo $(11,13)$ com paredes colabadas após desidratação (15, seta branca); fibras transversais e longitudinais lignificadas no endocarpo $(11-13,15)$ e exclusivamente longitudinais nas adjacências da zona de deiscência (15, seta preta). 10-12. Frutos adultos fechados. 13-15: Frutos abertos. 11-12. Azul de Toluidina. 13. Floroglucinol. 14-15. Safranina. En: endocarpo, Ex: exocarpo, FiN: fibras não-lignificadas, H: hipoderme, L: laticífero, M: mesocarpo. Barras = 10, 17: $2 \mathrm{~cm} ; 14: 500 \mu \mathrm{m} ; 15: 100 \mu \mathrm{m} ; 11,13: 50 \mu \mathrm{m} ; 12: 20 \mu \mathrm{m}$. 

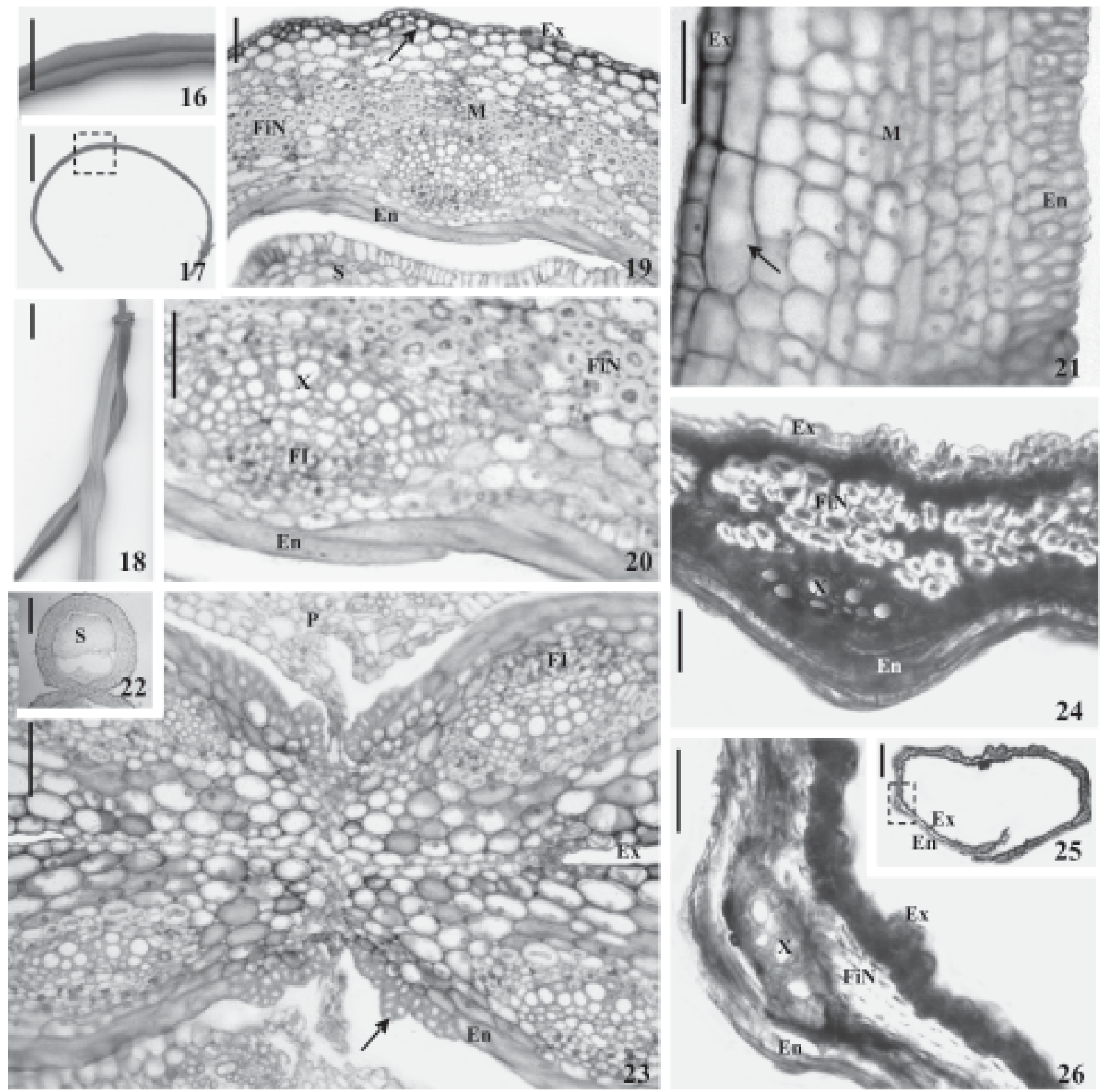

Figuras 16-26. Prestonia coalita (Vell.) Woodson. 16-17. Cápsula bicarpelar fechada (16: detalhe de 17). 18. Cápsula aberta. 19-26. Pericarpo (19-20, 22-26: ST; 21: SL; 20, 23 e 26: detalhes de 19, 22 e 25, respectivamente): colênquima uniestratificado (19, 21, seta); fibras longitudinais não-lignificadas no mesocarpo (19-20, 23-24), com paredes colabadas após desidratação total (26); fibras transversais lignificadas no endocarpo $(19-21,23,24)$ e longitudinais nas adjacências da zona de deiscência (23, seta); inversão do pericarpo após desidratação total (25-26). 16-17, 19-23. Frutos adultos fechados. 18, 24-26. Frutos abertos. 19-23. Azul de Toluidina. 24. Floroglucinol. 25-26. Safranina. En: endocarpo, Ex: exocarpo, FI: floema interno, FiN: fibras não-lignificadas, M: mesocarpo, P: placenta, S: semente, $\mathrm{X}$ : xilema. Barras $=16,18,22,25: 500 \mu \mathrm{m} ; 17: 2 \mathrm{~cm} ; 19-21,23-24,26: 50 \mu \mathrm{m}$. 
A deiscência do fruto em $P$. coalita ocorre através da separação dos septos e das margens dos carpelos. As placentas (Fig. 22-23) destacam-se do pericarpo após a ruptura sutural, constituindo dois eixos livres das valvas e onde as sementes ficam inseridas. Diferentemente do que ocorre nas síliquas, as placentas nesta espécie não constituem um eixo único ou replum, nem formam um septo falso. São estruturas tênues, que $\log$ o são levadas pelo vento, deixando as duas valvas do pericarpo ainda inseridas no receptáculo (Fig. 18). Barroso et al. (1999) tratam as cápsulas bicarpelares em Allamanda como loculicidas, mas este não é o caso em $P$. coalita, cujas peculiaridades não se encaixam nas descrições da literatura (Spjut 1994; Oliveira et al. 1978; Barroso et al. 1999; Hickey \& King 2002), sendo aqui denominada de cápsula bicarpelar septicida.

Frutos de muitas espécies de Prestonia são foliculares (Woodson Jr. 1936; Markgraf 1968; Ezcurra 1981), tais como P. calycina Müll. Arg., P. denticulata (Vell.) Woodson e P. riedelii (Müll. Arg.) Markgr. (Rio $\&$ Kinoshita 2005), às vezes apresentando os dois carpelos unidos apenas no ápice, separando-se na maturidade. Isto não ocorre com os frutos de $P$. coalita, pois eles não se separam em mericarpos, permanecendo com os carpelos conatos (Fig. 16-17, 22-23) até o momento da deiscência (Fig. 18). Fica assim demonstrada a ocorrência de dois tipos de frutos - folículos e cápsulas - dentro de um mesmo gênero (Prestonia).

Os resultados obtidos modificam as descrições dos frutos de $P$. coalita e, juntamente com a análise da literatura, apontam para a necessidade de se rever as descrições das espécies de Prestonia como um todo. Muitas destas plantas apresentam fortes indícios de que seus frutos possuem carpelos totalmente conatos, que possivelmente constituiriam cápsulas bicarpelares, conforme ilustrações de $P$. dusenii (Malme) Woodson (Markgraf 1968) e P. perplexa Woodson (Rio \& Kinoshita 2005). O exame de exsicatas de $P$. acutifolia evidenciou que esta espécie também possui cápsula bicarpelar, embora seja descrita como tendo pares de folículos unidos na extremidade (Woodson Jr. 1936; Rio \& Kinoshita 2005).

O tipo de cápsula encontrado em $P$. coalita ocorre em outras Apocynaceae. Os frutos de Temnadenia violacea examinados mostraram-se conatos em toda a sua extensão, assim como aqueles descritos como "folículos fusionados" em espécie de Nerium, por Thomas \& Dave (1991), bem como em Vallaris solanacea O.Ktze. e Wrightia tomentosa Roem. et Schult., por Thomas \& Dave (1994). Os frutos secos encontrados nestas plantas constituem cápsulas bicarpelares.

É possível que cápsulas bicarpelares foram descritas como folículos em outras espécies desta família. Folículos tipicamente delgados e posgenitamente fusionados são apontados para Parsonsia, Artia, Thenardia, Temnadenia e algumas espécies de Prestonia (Endress \& Bruyns 2000); entretanto a definição de folículo inclui que estes sejam monocarpelares (Spjut 1994; Barroso et al. 1999; Hickey \& King 2002), o que não ocorre quando os mesmos são fusionados, mesmo que posgenitamente; neste caso, tem-se a formação de fruto sincárpico bicarpelar (cápsula bicarpelar). Há indícios de que isto ocorra com outras Apocynaceae, conforme a análise das ilustrações de frutos de Parsonsia flexuosa Bail. e P. terminalifolia Guillaumin (Hamel 1983), Temnadenia stellaris (Lindl.) Miers (Markgraf 1968), Malouetia tamaquarina A.DC. e M. lanceolata Müll. Arg. (Müeller 1860). A análise da literatura sugere que possivelmente nestes táxons ocorram cápsulas bicarpelares, tal como aqui constatado para $P$. coalita, indicando a necessidade de estudos adicionais e mais amplos sobre os frutos secos nesta família a fim de aprofundar esta questão morfológica.

Frutos capsulares são assinalados para outras Apocynaceae s.s., como Allamanda L. (Sakane \& Shepherd 1986; Rosatti 1989), mas neste gênero eles são curtos, achatados e mais ou menos elípticos, nunca tão alongados e estreitos como os de Prestonia coalita, P. acutifolia e Temnadenia violacea. Cápsulas também são apontadas para Plectaneia Thou. (Endress \& Bruyns 2000), neste caso sendo alongadas, mas não tão estreitas quanto em Prestonia.

Entre os onze gêneros aqui levantados que comprovada ou possivelmente apresentam cápsulas bicarpelares, nove estão circunscritos em tribos de Apocynoideae, sendo que Allamanda (Plumerieae) e Plectaneia (Alyxieae) posicionam-se em tribos mais derivadas de Rauvolfioideae, conforme sistema de Endress \& Bruyns (2000). Cinco gêneros (Artia, Parsonsia, Prestonia, Temnadenia e Thenardia) pertencem a Echiteae, que é a tribo mais derivada de Apocynoideae. Isto evidencia que a cápsula bicarpelar é um estado de caráter apomórfico em relação aos plesiomórficos folículos encontrados dentro dessas duas subfamílias.

A maior diversidade morfológica dos frutos em Apocynaceae s.l. é encontrada em Rauvolfioideae, que é a subfamília mais basal do grupo. Através do presente 
trabalho, ampliaram-se os tipos de frutos que ocorrem em Apocynoideae, que já foi apontada como tendo apenas folículos (Endress \& Bruyns 2000; Simões \& Kinoshita 2002), os quais aparentemente predominam amplamente nas subfamílias mais derivadas (Periplocoideae, Secamonoideae e Asclepiadoideae). A inovação das cápsulas bicarpelares surgiu em diferentes momentos ao longo da evolução, tanto em Rauvolfioideae, quanto em Apocynoideae, sem constituir sinapomorfia para nenhuma de suas tribos. Tal inovação ocorreu inclusive dentro de um mesmo gênero, Prestonia, em que há grande número de espécies com folículos gêmeos e considerados apocárpicos.

Cápsulas bicarpelares não parecem ter surgido nas três subfamílias mais derivadas de Apocynaceae s.l. (Periplocoideae, Secamonoideae e Asclepiadoideae), em que predomina uma certa homogeneidade dos folículos. Em Asclepiadoideae, constituiu-se uma inovação peculiar a ocorrência de pares de folículos inflados em Calotropis, o que poderia sugerir adaptação para hidrocoria, mas estes frutos abrem-se e liberam as sementes comosas (anemocoria). Câmaras amplas no mesocarpo armazenam ar em espécies deste gênero (Kuriachen et al. 1991; 1992).

Os fatores ou pressões seletivas que resultaram na consolidação de inovações como os folículos de Calotropis ou as cápsulas bicarpelares permanecem ainda por serem determinados e, no caso das cápsulas, estes fatores parecem não ter atuado ao longo da evolução das três subfamílias mais derivadas, ficando restritos às mais basais (Rauvolfioideae e Apocynoideae).

Os frutos examinados apresentam uma pequena porção conata na base, que pode ser identificada através da morfologia externa. Esta região foi descrita no ovário destas plantas (Woodson Jr. \& Moore 1938; Gomes \& Cavalcanti 2001), correspondendo à conação carpelar que pouco se desenvolve na formação dos frutos considerados apocárpicos nesta família.

Em estudos anatômicos de frutos, o exocarpo, mesocarpo e endocarpo podem ser interpretados em sensu stricto - s.s., conforme se originem da epiderme externa, mesofilo e epiderme interna dos carpelos ovarianos, respectivamente. A abordagem ontogenética é essencial para este tipo de interpretação, que é adotada em diversos trabalhos (Pietrobom \& Oliveira 2004; Souto \& Oliveira 2005). Já o estudo destas camadas em sensu lato - s.l. - segue um conceito funcional, segundo o qual o exocarpo e o endocarpo são definidos como as regiões externa e interna do pericarpo, respectivamente, que exercem funções mecânicas ou de revestimento, enquanto que o mesocarpo compreende os tecidos entre estas duas regiões. Alguns trabalhos trazem abordagem ontogenética da formação das camadas do pericarpo, mas adotam, por exemplo, os conceitos de exocarpo s.l. (Marzinek \& Mourão 2003), ou de endocarpo s.l. (Mourão \& Beltrati 2001).

Os conceitos de exo, meso e endocarpo s.l. têm a vantagem de relacionar melhor as características destas regiões com os mecanismos de deiscência do fruto e têm sido adotados em estudos anatômicos de frutos de espécies de Apocynaceae (Thomas \& Dave 1991; 1994), assim como em abordagens morfológicas sobre estas plantas (Amaro et al. 2006), o que foi aqui adotado.

Exocarpo - Nas três espécies estudadas, o exocarpo possui epiderme uniestratificada, diferindo pela presença de colênquima com uma camada de células (Fig. 19, 21) ou várias (Fig. 3-4), ou pela ausência desta camada (Fig. 11). O colênquima subepidérmico foi considerado como parte do exocarpo s.l. aqui e em outros trabalhos, sendo que exocarpo uni ou pluriestratificado foi descrito para diferentes espécies de Apocynaceae s.l., distribuídas em diferentes subfamílias (Zala et al. 1976; Souza \& Moscheta 1992; Thomas \& Dave 1991; 1994; Kuriachen et al. 1990; 1991; 1992), não tendo sido identificado um padrão quanto a este caráter.

As contrastantes lenticelas no fruto de Aspidosperma parvifolium surgem a partir de um felogênio diferenciado logo abaixo dos estômatos da epiderme externa do ovário em A. polyneuron (Souza \& Moscheta 1992), o que possivelmente ocorre também com A. parvifolium.

As lenticelas são muito esparsas em Mesechites mansoana e Prestonia coalita, que possuem frutos muito mais estreitos (Fig. 10, 16-18) do que os de A. parvifolium (Fig. 1-2), o que poderia sugerir uma associação entre abundância de lenticelas com maior desenvolvimento lateral do fruto. No entanto, o folículo de A. polyneuron é subcilíndrico e estreito, típico da Secção Polyneura (Marcondes-Ferreira \& Kinoshita 1996), desenvolvendo-se bem menos em largura do que o folículo fortemente dolabriforme de A. parvifolium (Fig. 1-2), mas ambos apresentam lenticelas numerosas, corroborando que a ocorrência destas estruturas nos frutos independe da expansão dos tecidos em decorrência do crescimento, conforme apontado por Roth (1977). 
Mesocarpo - Há diferenças anatômicas acentuadas no mesocarpo dos frutos estudados, o qual é muito mais espesso em A. parvifolium, principalmente porque possui maior quantidade de tecido parenquimático do que em $M$. mansoana e $P$. coalita. Esclereídes são abundantes nesta região em A. parvifolium (Fig. 3, 7, 9), o que também ocorre em A. polyneuron (Souza \& Moscheta 1992), contribuindo para a sustentação mecânica destes frutos secos. O mesmo não ocorre nas outras duas espécies estudadas, pois não apresentam tanta lignificação no mesocarpo.

Fibras não-lignificadas formam bainhas nos feixes vasculares em M. mansoana (Fig. 11, 15), ou constituem um anel descontínuo, chegando a ter cerca de $1 / 3$ da espessura do mesocarpo em $P$. coalita (Fig. 19-20, 23), mas estão ausentes no mesocarpo de A. parvifolium (Fig. 3-9). Nesta última espécie, ocorre lignificação tardia no endocarpo (Fig. 3, 5, 8-9), o que poderia ocorrer no mesocarpo das outras espécies. $\mathrm{O}$ teste com Floroglucina eliminou esta possibilidade, revelando que as fibras mesocárpicas em $M$. mansoana e $P$. coalita permanecem não-lignificadas em frutos abertos, que já liberaram suas sementes (Fig. 13, 24). A espessura da parede celular destas fibras não-lignificadas indica que elas contribuem para a sustentação mecânica dos órgãos em que ocorrem.

Fibras não-lignificadas diferem daquelas com camada gelatinosa, pois estas últimas possuem parede celular com uma camada interna rica em celulose, altamente hidrofílica, que, quando desidratada, afasta-se da camada mais externa e lignificada (Esau 1972; Marcati et al. 2001; Luchi 2004). As fibras não-lignificadas aqui identificadas não têm esta distinção em duas camadas, possuindo parede espessa e sem impregnação de lignina, tendo-se evidenciado um conteúdo básico em seu lume (Fig. 11, 13, 19, 23-24, 26). Gorshkova \& Morvan (2006) adotam fibras não-lignificadas como sinônimo de gelatinosas, o que não é seguido aqui.

Bainha de fibras septadas não-lignificadas e com protoplasto ativo foi descrita no floema do pulvino em Pterodon pubescens Benth. (Fabaceae, Faboideae), possivelmente com a função de reserva (Machado \& Rodrigues 2004), o que talvez ocorra também nas espécies aqui estudadas. A presença de fibras gelatinosas em plantas do Cerrado já foi relacionada com a formação do lenho de tensão (Paviani 1974), mas posteriormente lhes foi atribuída a função de armazenar água, especialmente em xilopódios (Paviani 1977; 1978), o que aqui se propõe também para as fibras não-lignificadas dos frutos. Estas conjecturas necessitam ser analisadas melhor à luz especialmente de dados ultraestruturais.

Fibras longitudinais foram descritas no fruto de diferentes espécies de Apocynaceae s.l., formando uma bainha no feixe vascular ou um anel no mesocarpo (Thomas \& Dave 1991; 1994). Fibras celulósicas mesocárpicas foram assinaladas em espécies de Asclepiadoideae (Kuriachen et al. 1990; 1992). É possível que estas fibras sejam não-lignificadas, mas não foi realizado teste histoquímico específico para confirmar isto. Já no pecíolo de uma espécie de Himatanthus (Larrosa \& Duarte 2005), foi confirmada a ausência de lignificação em grupos de fibras associados aos feixes vasculares, à semelhança do que foi relatado para $M$. mansoana e $P$. coalita. A presença destas fibras pode representar um estado apomórfico em relação à sua ausência e possivelmente constituem estruturas que auxiliam no mecanismo de abertura do fruto.

Laticíferos são abundantes e largos no mesocarpo em Aspidosperma parvifolium (Fig. 3, 7) e podem ser do tipo ramificado (Fig. 6); não foram localizados septos ou seus resquícios que evidenciassem articulação nos mesmos. Eles são descritos como altamente ramificados e não articulados no mesocarpo de uma espécie de Nerium (Thomas \& Dave 1991) e em folhas de Himatanthus lancifolius (Müll.Arg.) Woodson (Barros 1988). Contrapondo-se a isto, análise ontogenética demonstrou que estes canais secretores são articulados em A. australe Müll. Arg. (Rauvolfioideae) e Blepharodon bicuspidatum E. Fourn. (Asclepiadoideae), originando-se através da rápida destruição das paredes de células contíguas, que se anastomosam precocemente, diferenciando-se em canais que aparentam ausência de articulação, segundo Demarco et al. (2006). Estes autores comprovaram que a identificação do tipo de laticífero requer estudo ontogenético e seus resultados ajudaram a esclarecer a controvérsia na literatura sobre estas estruturas secretoras em Apocynaceae.

Idioblastos secretores são numerosos no mesocarpo de Mesechites mansoana, inclusive constituindo uma hipoderme secretora (Fig. 11), possivelmente com conteúdo de compostos fenólicos. Esta peculiaridade anatômica também está presente na flor desta espécie e de outras de Macrosiphonia, Mandevilla e Secondatia (Simões et al. 2006), bem como em diferentes órgãos de espécies de Forsteronia (Rio et al. 2005) e Mandevilla (Appezzato-da-Glória \& Estelita 2000). Todos estes gêneros pertencem à Mesechiteae, Apocynoideae (Simões et al. 2004). 
M. de M. Castro (com. pess. 2005) atentou para a presença destes idioblastos em diferentes espécies desta tribo.

A ocorrência de feixes vasculares anficrivais no mesocarpo de Aspidosperma parvifolium (Fig. 3, 8) difere da anatomia das folhas de A. tomentosum Mart., em que foram encontrados feixes bicolaterais (Morretes \& Ferri 1959). Há os dois tipos de feixes no mesocarpo de A. polyneuron (Souza \& Moscheta 1992). Os feixes vasculares são bicolaterais e mais próximos do endocarpo do que do exocarpo em Mesechites mansoana (Fig. 11) e Prestonia coalita (Fig. 19), enquanto que eles posicionam-se no mesocarpo externo em Calotropis procera (Kuriachen et al. 1991). Feixes anficrivais ou bicolaterais são apontados entre as características anatômicas das Apocynaceae (Metcalfe \& Chalk 1957).

Os feixes vasculares em $P$. coalita (Fig. 19-20, 23) apresentam o floema externo (voltado para a região externa do fruto) mais abundante do que o interno (voltado para o lóculo), o que também ocorre no caule de Vinca minor L. (Fjell 1983). Esta desproporção entre floema interno e externo é menos acentuada em M. mansoana (Fig. 11). Possivelmente o posicionamento mais interno dos feixes no pericarpo, bem como a redução do floema externo e a maior quantidade de floema interno, juntamente com a proteção dos feixes vasculares por camadas de fibras tenham trazido a vantagem adaptativa de restringir o acesso de fitófagos à região com maior volume de seiva elaborada, notadamente em $P$. coalita, características estas ausentes no pericarpo da basal A. parvifolium (Fig. 3, 8). Estas características parecem constituir estados apomórficos em relação ao plesiomorfismo que se pode associar ao posicionamento mais externo dos feixes vasculares, floema externo abundante ou grupos de fibras reduzidos ou ausentes no mesocarpo.

Endocarpo - O endocarpo é esclerenquimático nas três espécies estudadas, sendo que suas fibras podem ser não-lignificadas em frutos adultos de $A$. parvifolium (Fig. 3, 5, 8). O teste com Floroglucina realizado em frutos abertos comprovou a lignificação tardia do endocarpo nesta espécie (Fig. 9), fenômeno este ausente nas outras plantas estudadas. $\mathrm{O}$ endocarpo do folículo de Calotropis procera (Asclepiadoideae) torna-se lignificado justo antes da deiscência (Kuriachen et al. 1991). Esta característica possibilitaria uma melhor acomodação das sementes no lóculo ao longo de seu desenvolvimento (Roth 1977).

O entrelaçado de fibras com diferentes orientações no endocarpo constitui camadas mais numerosas em
A. parvifolium (Fig. 3, 5, 8, 9) e A. polyneuron (Souza \& Moscheta (1992) do que em M. mansoana (Fig. 11-12), sendo que o número de estratos é menor em $P$. coalita (Fig. 19-21). No primeiro caso, constitui o endocarpo externo, mediano e interno; no segundo, suprimiu-se o endocarpo mediano e na última espécie só há uma camada.

O endocarpo externo tem fibras longitudinais e o interno possui fibras transversais em A. parvifolium e $M$. mansoana. Já em $P$. coalita, as fibras desta região chegam a ser quase exclusivamente transversais (Fig. 19-21), exceto nas adjacências da zona de deiscência (Fig. 15, 23). Fibras longitudinais do endocarpo estão ausentes em oito das nove espécies de Asclepiadoideae relatadas na literatura, nas quais predominam espécies com até cinco camadas de fibras transversais ou levemente oblíquas (Kuriachen et al. 1990; 1991; Thomas \& Dave 1994).

Estes resultados indicam uma redução no número de camadas do endocarpo ao longo da evolução de Apocynaceae s.l. Aparentemente, houve uma diminuição seguida pela supressão das fibras longitudinais nesta região. Este fenômeno parece ter-se consolidado no endocarpo mais estreito e exclusivamente com fibras transversais que predomina na subfamília mais derivada, Asclepiadoideae, significando uma economia de recursos biológicos na construção da unidade de reprodução.

Este processo evolutivo ocorreu sem perdas adaptativas aparentes, mas possivelmente com ganhos na eficiência de liberação das sementes. O teste de desidratação total do pericarpo corrobora esta afirmação, já que o endocarpo mais estreito e predominantemente com fibras transversais em P. coalita (Fig. 25-26) mostrou-se capaz de liberar suas sementes com eficiência aparentemente superior ao daquele em M. mansoana, que é mais espesso e com fibras transversais e longitudinais (Fig. 14-15).

A presença de fibras estritamente longitudinais adjacentes à zona de deiscência do fruto em Mesechites mansoana (Fig. 15) e Prestonia coalita (Fig. 22-23) é semelhante ao que Fahn (1990) relata para certos legumes. Tais fibras possivelmente orientam o plano de separação dos carpelos e condicionam o destacamento do eixo placentário em que as sementes comosas se inserem.

Estudos ontogenéticos em espécies de Fabaceae mostraram que as camadas fibrosas do endocarpo são formadas a partir da epiderme ovariana uniestratificada, que sofre divisões periclinais após a fecundação (Pietrobom \& Oliveira 2004; Nakamura \& Oliveira 
2005). Este tipo de divisão não ocorre em Aspidosperma polyneuron (Apocynaceae), em que há um tecido interno pluriestratificado diferenciado já no ovário da flor em pré-antese, o qual origina o endocarpo (Souza \& Moscheta 1992). Ainda não foi estabelecida a ontogênese destas camadas ovarianas em espécies de Apocynaceae, não sendo possível determinar se estes estratos celulares constituem uma epiderme interna pluriestratificada ou se é formado por uma epiderme interna uniestratificada com uma hipoderme adjacente à mesma.

Deiscência - As características do pericarpo são importantes para o entendimento do mecanismo de deiscência dos frutos. O folículo de Banksia (Proteaceae) abre-se como resultado do estresse que se desenvolve entre as células esclerenquimáticas do endocarpo e as do mesocarpo e exocarpo, as quais diferem na orientação das microfibrilas de celulose de suas paredes celulares (Fahn 1990). Hoffmann (1931 apud Roth 1977) propôs que as tensões provocadas pela desidratação do parênquima do mesocarpo em contraposição com o tecido de resistência (o esclerênquima do endocarpo) resultaria na ruptura sutural, constituindo o mecanismo xerocástico de abertura do folículo em Aspidosperma megalocarpon (Apocynaceae).

O mecanismo xerocástico pode ser aplicado para o entendimento do fenômeno da deiscência em folículos de A. parvifolium e M. mansoana, podendo também ser estendido para a cápsula de $P$. coalita. Nestas três espécies, o exocarpo e o mesocarpo são regiões menos lignificadas do que o endocarpo que, uma vez desidratadas, diminuem de volume. Isto gera uma contração dos tecidos na região dorsal do pericarpo, produzindo uma tensão que promove a ruptura dos tecidos suturais, que é a região em queo endocarpo é mais frágil. $\mathrm{O}$ resultado disto é o recurvamento do pericarpo, expondo as sementes aladas ou comosas ao vento. As fibras do endocarpo estiram-se e constituem a camada de resistência às tensões, impedindo a fragmentação do fruto. Souza \& Moscheta (1992) já reconheciam este tecido como fator necessário para uma deiscência ativa do pericarpo.

Os resultados do teste de desidratação total do pericarpo de M. mansoana (Fig. 14-15) e de P. coalita (Fig. 25-26) sustentam a propriedade do mecanismo xerocástico. O recurvamento das ST do pericarpo foi bem maior na segunda espécie do que na primeira, o que pode ser atribuído a que o mesocarpo é mais estreito e suas fibras não-lignificadas são mais abundantes em P. coalita (Fig. 19-20, 24) do que em M. mansoana (Fig. 11, 13).

Postula-se aqui que as fibras não-lignificadas nestas espécies armazenam água em suas paredes de modo semelhante ao que é relatado para as fibras com camadas gelatinosas (Paviani 1977; 1978), ao mesmo tempo em que contribuem para a sustentação mecânica dos frutos sem o enrijecimento que a lignificação traz. O método aqui desenvolvido para o estudo anatômico do pericarpo totalmente desidratado (em etanol 100\%) revelou que nestas condições as fibras não-lignificadas do mesocarpo apresentam paredes colabadas, que redundam na diminuição de seu lume (Fig. 15, 26). Estas características tornam a redução do volume do pericarpo mais acentuada em $P$. coalita do que em M. mansoana, quando sob $0 \%$ de umidade, sendo que na primeira espécie o pericarpo pode reduzir-se em ca. 30-50\% da espessura original, enquanto na segunda, apenas ca. $10 \%$.

Enfatiza-se que estes dados são teóricos, pois o teste de desidratação total é bastante extremado e não corresponde ao teor de umidade dos frutos na natureza. É preciso avaliação no campo para verificar se estas conjecturas são verdadeiras ou não. Por outro lado, este teste tem certa utilidade na interpretação do mecanismo de deiscência dos frutos, pois avalia o potencial de recurvamento máximo que o pericarpo pode alcançar, quando totalmente desidratado. Este dado é útil em comparações entre espécies, como efetuado no presente estudo. Estudos adicionais de comparação morfométrica entre fibras não-lignificadas hidratadas e desidratadas poderiam dimensionar suas variações de volume, esclarecendo melhor seu papel no mecanismo de deiscência.

Adicionalmente ao efeito xerocástico, tem-se o papel da orientação das fibras do endocarpo no mecanismo de deiscência dos frutos, não apenas como tecido de resistência, mas que também pode orientar o plano de ruptura sutural. Estas fibras lignificadas formam grupos exclusivamente longitudinais adjacentes à zona de sutura carpelar em M. mansoana (Fig. 15) e $P$. coalita (Fig. 23), exceto em uma pequena região em que se inserem as placentas. Esta região de tecidos mais frágeis é que se rompe (Fig. 15) guiada pelas fibras longitudinais que a ladeiam. A própria ruptura dos tecidos do pericarpo na zona sutural promove também a liberação do eixo placentário nos frutos destas duas espécies, facilitando assim uma maior exposição das sementes comosas ao vento.

O plano de deiscência do folículo em Aspidosperma parvifolium não é guiado por fibras 
longitudinais e as placentas continuam unidas ao pericarpo após a deiscência do folículo (Fig. 2). Nesta espécie, a zona de deiscência encontra-se pré-formada no pericarpo, com a epiderme diferenciada (Fig. 7), tornando os bordos carpelares conspícuos e distintos entre si na região sutural. Em A. polyneuron, a região de deiscência se diferencia muito cedo e já se encontra pré-formada desde o ovário, em uma linha demarcada já nos carpelos do botão em pré-antese; esta característica facilita posteriormente o fendilhamento do folículo para a liberação das sementes (Souza \& Moscheta 1992), sendo apontada como típica dos ovários monocarpelares (Roth 1977). Este tipo de sutura pode ser identificada no ovário de outras espécies de Apocynaceae basais: Catharanthus roseus L. (Zala et al. 1976) e A. triternatum Rojas Acosta (Marcondes-Ferreira \& Kinoshita 1996) e Himatanthus drasticus drasticus (Mart.) M.M. Plumel (Amaro et al. 2006).

Costas ou saliências internas correspondem a diferenças na espessura do pericarpo, em que a região com feixe vascular é mais espessa do que a intervascular, formando ondulações na face interna do fruto. Esta característica anatômica possivelmente torna mais eficiente o processo de deiscência, pois aumenta a superfície interna do endocarpo, possibilitando seu melhor estiramento. Estas costas internas do pericarpo estão ausentes em A. parvifolium (Fig. 3), sendo muito suaves nas outras duas espécies estudadas (Fig. 11, 19) e em uma espécie de Nerium (Thomas \& Dave 1991). As costas internas são notáveis em Catharanthus pusillus (Murr.) G.Don. (Thomas \& Dave 1994) e C. roseus (Zala et al. 1976), em que ocupam cerca da metade da espessura do pericarpo no fruto fechado.

Outros aspectos - Roth (1977) salienta que o pericarpo geralmente tem grande utilidade taxonômica, mas é pouco considerado em estudos evolutivos e em considerações sobre a filogenia das plantas. A partir do presente estudo morfo-anatômico, destacam-se os seguintes caracteres do fruto como úteis na taxonomia de Apocynaceae s.l.: simetria, número de regiões no meso e endocarpo; epicarpo uni ou pluriestratificado; lenticelas contrastantes ou não; camadas subepidérmicas formadas por colênquima ou hipoderme secretora; espessura do mesocarpo, com ou sem aerênquima, com ou sem esclereídes, com ou sem fibras não-lignificadas em bainhas dos feixes vasculares ou em anel; espessura do anel de fibras nãolignificadas; presença ou não de idioblastos secretores no mesocarpo; quantidade e diâmetro dos laticíferos; feixes vasculares posicionados no mesocarpo externo, mediano ou interno; espessura do endocarpo e seu número de camadas, conforme a orientação de suas fibras; espessura das costas internas do pericarpo.

O folículo achatado e dolabriforme de Aspidosperma parvifolium (Fig. 1-2) é fortemente zigomorfo, enquanto que os frutos de Mesechites mansoana (Fig. 10) e Prestonia coalita (Fig. 16-17) são subcilíndricos e actinomórficos. Roth (1977) ponderou que, embora na flor a simetria radial seja um caráter derivado, no fruto dá-se o oposto, onde o folículo zigomórfico é considerado como o tipo de fruto mais primitivo entre as angiospermas, o que coaduna com a posição dos gêneros aqui estudados em filogenias da família (Potgieter \& Albert 2001; Sennblad \& Bremer 2002). Interpreta-se que A. parvifolium apresenta estados de caracteres do pericarpo que ilustram o plesiomorfismo entre os frutos secos de Apocynaceae s.s., enquanto que $P$. coalita reúne diferentes estados apomórficos, tais como fruto capsular e actinomórfico, com redução da espessura do pericarpo, fibras longitudinais não-lignificadas dispostas em um anel largo no mesocarpo, redução do floema externo, supressão do endocarpo externo formado por fibras longitudinais, restrição das fibras longitudinais do endocarpo à zona sutural, sutura constituída por tecido homogêneo e sem epiderme diferenciada, inserção das placentas na zona de deiscência e sua liberação no momento em que o fruto se abre.

Os idioblastos secretores e os laticíferos constituem defesas químicas que foram encontradas em maior ou menor grau entre as espécies estudadas. As fibras longitudinais não-lignificadas no mesocarpo de Mesechites mansoana e Prestonia coalita podem representar uma barreira químico-mecânica principalmente contra a herbivoria. Tais características, que variam entre as espécies, somam-se à última barreira protetora da semente, que é o endocarpo esclerenquimático, que também participa do mecanismo de deiscência do fruto.

As diferentes alternativas desenvolvidas evolutivamente e identificadas através do presente estudo morfológico e anatômico tiveram um mesmo resultado: a deiscência dos frutos, possibilitando a liberação de suas anemocóricas sementes. 


\section{Agradecimentos}

Agradecimentos ao CNPq, pela Bolsa de Doutorado, bem como ao Programa de Pós-Graduação em Biologia Vegetal e ao Laboratório de Anatomia Vegetal, ambos da Universidade Estadual de Campinas, que proporcionaram condições para o desenvolvimento do presente trabalho. Agradecimentos ao Shesterson Aguiar, por ter cedido parte do material botânico utilizado e ao Dr. Luiz Alfredo Rodrigues Pereira, pela gentileza da revisão do resumo.

\section{Referências bibliográficas}

Albers, F. \& Meve, U. 2001. A karyological survey of Asclepiadoideae, Periplocoideae, and Secamonoideae, and evolutionary considerations within Apocynaceae s.l. Annals of the Missouri Botanical Garden 88: 624-656.

Amaro, M.S.; Medeiros Filho, S.; Guimarães, R.M. \& Teófilo, E.M. 2006. Morfologia de frutos, sementes e de plântulas de janaguba (Himatanthus drasticus (Mart.) Plumel. Apocynaceae). Revista Brasileira de Sementes 28: 63-71.

Appezzato-da-Glória, B. \& Estelita, M.E.M. 2000. Development, structure and distribution of colleters in Mandevilla illustris e M. velutina (Apocynaceae). Revista Brasileira de Botânica 23: 113-120.

Barros, C.F. 1988. Himatanthus lancifolius (Müell.Arg.) Woodson (Apocynaceae). Anatomia foliar. Rodriguésia 38/40: 33-39.

Barroso, M.B.; Morin, N.P.; Peixoto, A.L. \& Ichaso, C.L.F. 1999. Frutos e sementes: morfologia aplicada à sistemática de dicotiledôneas. Viçosa, Editora da UFV.

Costa, I.R.; Araújo, F.S. \& Lima-Verde, L.W. 2004. Flora e aspectos auto-ecológicos de um encrave de cerrado na chapada do Araripe, Nordeste do Brasil. Acta Botanica Brasilica 18: 759-770.

Demarco, D.; Kinoshita, L.S. \& Castro, M.M. 2006. Laticíferos articulados anastomosados - novos registros para Apocynaceae. Revista Brasileira de Botânica 29: 133-144.

Duarte, A.P. 1970. Contribuição para uma revisão do gênero Aspidosperma. Anais da Academia Brasileira de Ciências 42: 289-327.

Endress, M.E. \& Bruyns, P.V. 2000. A revised classification of the Apocynaceae s.l. Botanical Review 66: 1-56.

Esau, K. 1972. Anatomía vegetal. $2^{a}$ ed. Barcelona, Omega.

Ezcurra, C. 1981. Revisión de las apocináceas de la Argentina. Darwiniana 23: 367-474.

Fahn, A. 1990. Plant Anatomy. Oxford, Pergamon Press.

Fjell, I. 1983. Anatomy of the xeromorphic leaves of Allamanda neriifolia, Thevetia peruviana and Vinca minor (Apocynaceae). Nordic Journal of Botany 3: 383-392.

Gomes, S.M. \& Cavalcanti, T.B. 2001. Morfologia floral de Aspidosperma Mart \& Zucc. (Apocynaceae). Acta Botanica Brasilica 15: 73-88.
Gorshkova, T. \& Morvan, C. 2006. Secondary cell-wall assembly in flax phloem fibres: role of galactans. Planta 223: $149-158$.

Hamel, M.-C. 1983. Contribution bibliographique à la connaissance botanique des Apocynacées. I. Les données morphologiques et biologiques. Revue Generale de Botanique 90: 221-300.

Hickey, M. \& King, C. 2002. The Cambridge illustrated glossary of botanical terms. Cambridge, Cambridge University Press.

Johansen, D.A. 1940. Plant microtechnique. New York, McGraw-Hill Book.

Judd, W.S.; Campbell, C.S.; Kellogg, E.A. \& Stevens, P.F. 1999. Plant systematics: a phylogenetic approach. Sunderland, Sinauer Associates.

Kinoshita, L.S. (coord.). 2005. Apocynaceae. Pp. 35-36. In: M.G.L. Wanderley; G.J. Shepherd; T.S. Melhem \& A.M. Giulietti (eds.). Flora Fanerogâmica do Estado de São Paulo. v.4. São Paulo, FAPESP/HUCITEC.

Kuriachen, P.M.; Thomas, V.; Dave, Y. 1990. Morphohistogenic studies in the follicle of Tylophora dalzellii Hk. F. Phytomorphology 40: 349-357.

Kuriachen, P.M.; Dave, Y.; Thomas, V. 1991. Development, structure and dehiscence of follicles of Calotropis procera (Ait.) R. Br. (Asclepiadaceae). Korean Journal of Botany 34: 107-112.

Kuriachen, P.M.; Thomas, V. \& Dave, Y. 1992. Taxonomic and phylogenetic significance of fruit walls in Asclepiadaceae. Feddes Repertorium 103: 179-193.

Larrosa, C.R.R. \& Duarte, M.R. 2005. Contribuição ao estudo anatômico do caule de Himatanthus sucuuba (Spruce ex Müll.Arg.) Woodson, Apocynaceae. Revista Brasileira de Farmacognosia/ Brazilian Journal of Pharmacognosy 15: 110-114.

Luchi, A.E. 2004. Anatomia do lenho de Croton urucurana Baill. (Euphorbiaceae) de solos com diferentes níveis de umidade. Revista Brasileira de Botânica 27: 271-280.

Machado, S.R. \& Rodrigues, T.M. 2004. Anatomy and ultrastructure the primary pulvinus of Pterodon pubescens Benth. (Fabaceae - Faboideae). Revista Brasileira de Botânica 27: 135-147.

Marcati, C.R.; Angyalossy-Alfonso, V. \& Benetati, L. 2001. Anatomia comparada do lenho de Copaifera langsdorffii Desf. (Leguminosae-Caesalpinoideae) de floresta e cerradão. Revista Brasileira de Botânica 24: 311-320.

Marcondes-Ferreira, W. \& Kinoshita, L.S. 1996. Uma nova divisão infragenérica para Aspidosperma Mart. (Apocynaceae). Revista Brasileira de Botânica 19: 203-214.

Markgraf, F. 1968. Apocináceas. Pp. 1-112. In: P.R. Reitz (ed.). Flora Ilustrada Catarinense. Itajaí, Herbário Barbosa Rodrigues.

Marzinek, J. \& Mourão, K.S.M. 2003. Morphology and anatomy of the fruit and seed in development of Chorisia speciosa A.St.-Hil. - Bombacaceae. Revista Brasileira de Botânica 26: 23-34.

Metcalfe, C.R. \& Chalk, L. 1957. Anatomy of the dicotyledons - leaves, stem, and wood in relation to taxonomy with notes on economic uses. Oxford, Clarendon Press. 
Morales, J.F. 1997. A synopsis of the genus Prestonia (Apocynaceae) Section Tomentosae in Mesoamerica. Novon 7: 59-66.

Morretes, B.L. \& Ferri, M.G. 1959. Contribuição ao estudo da anatomia das folhas de plantas do cerrado. Boletim da Faculdade de Filosofia Ciências e Letras da Universidade de São Paulo 243 (série Botânica 16): 5-70.

Mourão, K.S.M. \& Beltrati, C.M. 2001. Morphology and anatomy of developing fruits and seeds of Vismia guianensis (Aubl.) Choisy (Clusiaceae). Revista Brasileira de Biologia 61: 147-158.

Müeller A.J. 1860. Apocynaceae. Pp. 1-196. In: K.P. von Martius (ed.). Flora Brasiliensis. Monachii, Frid. Fleischer. v.VI(1).

Nakamura, A.T. \& Oliveira, D.M.T. 2005. Morfoanatomia e ontogênese da sâmara de Pterocarpus violaceus Vogel (Fabaceae: Faboideae). Revista Brasileira de Botânica 28: 375-387.

Oliveira, A.D.O.; Menezes, E.M. \& Arens, K. 1978. Proposição de um sistema de classificação carpológica com base na morfogênese. Naturalia 3: 39-43.

Paviani, T.I. 1974. Sobre a ocorrência de fibras gelatinosas em Plathymenia reticulata Benth. Ciência \& Cultura 26: 783-786.

Paviani, T.I. 1977. Estudo morfológico e anatômico de Brasilia sickii G.M. Barroso. II. Anatomia da raiz, do xilopódio e do caule. Revista Brasileira de Biologia 37: 307-324.

Paviani, T.I. 1978. Anatomia vegetal e cerrado. Ciência \& Cultura 30: 1076-1086.

Pietrobom, R.C.V. \& Oliveira, D.M.T. 2004. Morfoanatomia e ontogênese do pericarpo de Schizolobium parahyba (Vell.) Blake (Fabaceae, Caesalpinioideae). Revista Brasileira de Botânica 27: 767-779.

Potgieter, K. \& Albert, V.A. 2001. Phylogenetic relationships within Apocynaceae s.l. based on $t r n \mathrm{~L}$ intron and $t r n \mathrm{~L}$ F spacer sequences and propagule characters. Annals of the Missouri Botanical Garden 88: 523-549.

Rio, M.C.S. \& Kinoshita, L.S. 2005. Prestonia (Apocynaceae) no Sul e Sudeste do Brasil. Hoehnea 32: 233-258.

Rio, M.C.S.; Kinoshita, L.S. \& Castro, M.M. 2005. Anatomia foliar como subsídio para a taxonomia de espécies de Forsteronia G. Mey. (Apocynaceae) dos cerrados paulistas. Revista Brasileira de Botânica 28: 713-726.

Rosatti, T.J. 1989. The genera of Suborder Apocynineae (Apocynaceae and Asclepiadaceae) in the Southeastern United States. Journal of the Arnold Arboretum 70: 307-401.

Roth, I. 1977. Fruits of Angiosperms. In: K. Linsbauer (ed.). Handbuch der Pflanzenanatomie v.10. Berlin-Stuttgart, Gebrüder Borntraeger.

Sakane, M. \& Shepherd, G.J. 1986. Uma revisão do gênero Allamanda L. (Apocynaceae). Revista Brasileira de Botânica 9: 125-149.
Sennblad, B. \& Bremer, B. 2002. Classification of Apocynaceae s.l. according to a new approach combining Linnaean and phylogenetic taxonomy. Systematic Biology 51: 389-409.

Simões, A.O.; Castro, M.M. \& Kinoshita, L.S. 2006. Calycine colleters of seven species of Apocynaceae (Apocynoideae) from Brazil. Botanical Journal of the Linnean Society 152: 387-398.

Simões, A.O.; Endress, M.E.; Niet, T.V.D.; Kinoshita, L.S. \& Conti, E. 2004. Tribal and intergeneric relationships of Mesechiteae (Apocynoideae, Apocynaceae): evidence from three noncoding plastid DNA regions and morphology. American Journal of Botany 91: 1409-1418.

Simões, A.O. \& Kinoshita, L.S. 2002. The Apocynaceae s.str. of the Carrancas region, Minas Gerais, Brazil. Darwiniana 40: $127-169$

Souto, L.S. \& Oliveira, D.M.T. 2005. Morphology, anatomy, and development of Byrsonima intermedia A.Juss. (Malpighiaceae) fruit and seed. Revista Brasileira de Botânica 28: 697-712.

Souza, L.A. \& Moscheta, I.S. 1992. Morfo-anatomia do fruto e da plântula de Aspidosperma polyneuron M.Arg. (Apocynaceae). Revista Brasileira de Biologia 52: 439-447.

Souza, V.C. \& Lorenzi, H. 2005. Botânica sistemática: guia para identificação das famílias de angiospermas da flora brasileira, segundo A.P.G.II. Nova Odessa, Plantarum.

Spjut, R.W. 1994. A systematic treatment of fruit types. Memoirs of The New York Botanical Garden 70: $1-182$.

Thomas, V. \& Dave, Y. 1991. Structure and development of follicles of Nerium indicum Mill. (Apocynaceae). Feddes Repertorium 102: 399-407.

Thomas, V. \& Dave, Y. 1994. Significance of follicle anatomy of Apocynaceae. Acta Societatis Botanicorum Poloniae 63: 9-20.

Torres, C. \& Galetto, L. 1999. Factors constraining fruit set in Mandevilla pentlandiana (Apocynaceae). Botanical Journal of the Linnean Society 129: 187-205.

Vasconcellos, M.B. \& Gouvea, L.S.K. 1993. As Apocynaceae da região de Poços de Caldas, Minas Gerais, Brasil. Acta Botanica Brasilica 7: 107-127.

Woodson Jr., R.E. 1936. Studies in the Apocynaceae IV- the American genera of Echitoideae. Annals of the Missouri Botanical Garden 23: 341-611.

Woodson Jr., R.E. 1951. Studies in the Apocynaceae, VIII. An interim revision of the genus Aspidosperma Mart. et Zucc. Annals of the Missouri Botanical Garden 38: 119-206.

Woodson Jr., R.E. \& Moore, J.A. 1938. The vascular anatomy and comparative morphology of apocynaceous flowers. Bulletim of the Torrey Botanical Club 65: 135-169.

Zala, J.V.; Patel, N.D. \& Dave, Y.S. 1976. Structure of the developing and dry pericarp of Catharanthus roseus (Apocynaceae). Flora 165: 355-360. 